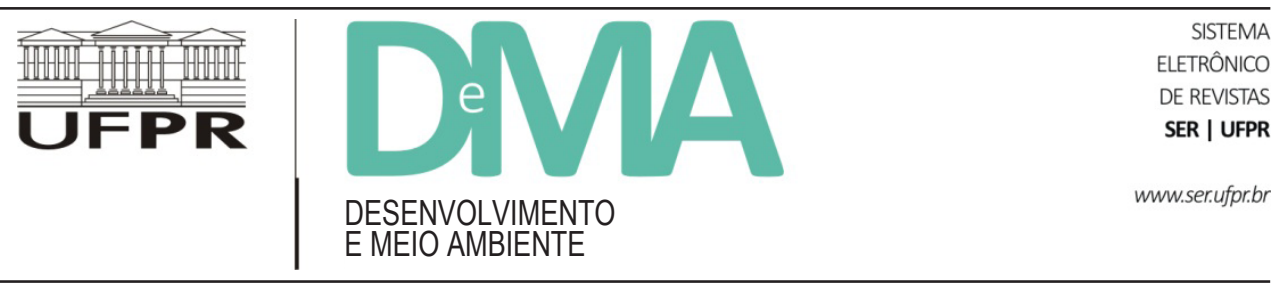

\title{
Desafios à cogestão: os impactos da Via Expressa Sul sobre o extrativismo na RESEX Marinha do Pirajubaé
}

\section{Challenges to Co-Management: the Impacts of the Southern Expressway on Resources Use in the Marine RESEX of Pirajubaé}

\author{
Juliana Lima SPÍNOLA ${ }^{1 *}$, Cristina Frutuoso TEIXEIRA ${ }^{1,2}$, José Milton ANDRIGUETTO FILHO ${ }^{1,3}$ \\ ${ }^{1}$ Programa de Pós-Graduação em Meio Ambiente e Desenvolvimento (PPGMADE), Universidade Federal do Paraná (UFPR), Curitiba, PR, Brasil. \\ ${ }^{2}$ Setor de Educação, Universidade Federal do Paraná (UFPR), Curitiba, PR, Brasil. \\ ${ }^{3}$ Departamento de Zootecnia, Universidade Federal do Paraná (UFPR), Curitiba, PR, Brasil. \\ *E-mail de contato: juliana.1.spinola@gmail.com
}

Artigo recebido em 13 de março de 2014, versão final aceita em 11 de setembro de 2014.

RESUMO Este artigo apresenta uma reflexão sobre os impactos socioambientais gerados pela instalação da Via Expressa Sul, um empreendimento do governo do Estado de Santa Catarina, sobre o extrativismo do berbigão (Anomalocardia brasiliana) na Reserva Extrativista (RESEX) Marinha do Pirajubaé, em Florianópolis (SC). Esse empreendimento causou impactos significativos sobre o ambiente marinho dessa RESEX, incluindo a perda de cerca da metade do banco do berbigão nessa área, e, consequentemente, sobre as práticas extrativistas e sua gestão. As transformações socioambientais decorrentes da construção da Via Expressa Sul deflagraram uma situação de desregulação no uso dos recursos pesqueiros, engendrando conflitos de uso e desencadeando uma situação de livre acesso na RESEX do Pirajubaé. No caso de Pirajubaé, quando se impuseram interesses de grupos sociais dominantes em conflito com os objetivos da RESEX, este arranjo institucional mostrou-se incapaz de proteger os recursos ambientais e de garantir os direitos da população extrativista sobre estes em seu território, como propõe esta modalidade de Unidade de Conservação. Essa constatação permite pôr em questão a eficácia do arranjo institucional RESEX para garantir a gestão compartilhada e a conservação dos recursos naturais de determinados territórios.

Palavras-chave: cogestão; RESEX Marinha do Pirajubaé; Via Expressa Sul.

ABSTRACT This article focuses on the case of the environmental impacts generated by the installation of the Southern Expressway, an enterprise of the State Government of Santa Catarina, on the extraction of berbigão (cockles; Anomalocardia brasiliana) in the Marine Extractive Reserve (RESEX, in the Portuguese acronym) Pirajubaé, in Florianópolis (SC). The project caused significant impacts on the marine environment of this RESEX, including the loss of about half of the cockle bank, and hence on extractive practices and their management. The socio-environmental changes resulting from the construction of the Southern Expressway led to a situation 
of deregulation in the use of fisheries resources, resulting in use conflicts and establishing a situation of open access to resources in the area. In the case of Pirajubaé, when interests of dominant social groups in conflict with the goals of the RESEX were imposed, its institutional arrangement proved unable to secure the rights of the local users or gatherers on the use of natural resources in its territory, which should be the main objective of this kind of Conservation Unit. This leads us to question the effectiveness of the RESEX as an institutional arrangement to ensure shared management and conservation of natural resources in a given territory.

Keywords: co-management; Marine RESEX of Pirajubaé; Southern Expressway.

\section{Introdução}

O presente artigo versa sobre os impactos socioambientais gerados pela construção da Via Expressa Sul, um empreendimento do Governo do Estado de Santa Catarina, sobre o extrativismo na Reserva Extrativista (RESEX) Marinha do Pirajubaé (SC). A RESEX é uma categoria de Unidade de Conservação (UC) de Uso Sustentável (BRASIL, 2000) que corresponde a um regime de cogestão, ou gestão compartilhada, dos recursos naturais de uso comum. Ela garante aos extrativistas o direito de uso dos recursos comuns em seu território. $\mathrm{O}$ Sistema Nacional de Unidades de Conservação (SNUC) estabelece que a RESEX “tem como objetivos básicos proteger os meios de vida e a cultura dessas populações e assegurar o uso sustentável dos seus recursos naturais" (BRASIL, 2000). Aliada à garantia de acesso, a RESEX estabelece o regime de cogestão dos seus recursos de uso comum. Através do Conselho Gestor, os extrativistas têm o direito de participar das deliberações relativas ao uso e à conservação dos recursos naturais da RESEX, ao lado do ICMBio, órgão federal responsável pela UC, e de outras instituições que possuem interesses na área.

Uma importante discussão que se insere na Abordagem dos Comuns é aquela acerca dos regimes sob os quais esses recursos podem ser geridos com intuito de garantir seu uso de forma sustentável (Hardin, 1968; Berkes et al., 1989; Dietz et al., 2002; McKean, 1992; Ostrom, 2000; Fenny et al., 2001; Vieira et al., 2005; Kalikoski, 2007; Berkes, 2009; Medeiros, 2009). Essa abordagem tem permitido aos pesquisadores compreenderem os fatores que influenciam as condições e os problemas em torno do uso sustentável do pool dos recursos naturais de uso comum.

Diversos estudos (McKean, 1992; McKean, 2000; Vieira et al., 2005; Kalikoski, 2007; Berkes, 2009;
Medeiros, 2009; Berkes, 2010) defendem que a formulação e a implantação de instituições formais, para a gestão destes recursos, devem reconhecer e incorporar os conhecimentos e as práticas dos usuários e das instituições informais por eles subsidiadas. Caso contrário, essas instituições podem entrar em colapso, gerando a degradação dos recursos naturais e a desestruturação de sistemas socioprodutivos implicados. Neste sentido, o apoio governamental às instituições comunitárias através do estabelecimento de arranjos formais de cogestão ou de gestão compartilhada, como é o caso da RESEX, é altamente recomendado (Chamy, 2004; Kalikoski, 2007). Os mesmos estudos consideram que as instituições de cogestão, por permitirem a inclusão dos usuários nas tomadas de decisões e a divisão de responsabilidades entre eles e o governo, levam à maior legitimidade das regras de manejo e ao aumento da obediência a elas, garantindo o uso sustentável dos recursos naturais de uso comum.

Dentre os estudos acerca das RESEX Marinhas no Brasil, apenas alguns abordam a eficácia do arranjo de cogestão engendrado por esta categoria de UC no uso sustentável dos recursos pesqueiros. Destacam-se os estudos de Silva (2004) sobre a RESEX de Arraial do Cabo (RJ), de Prost (2007; 2010), que realizou uma análise comparativa entre as RESEX marinhas do Pará e a da Baía do Iguape (BA), de Vivacqua (2012), que analisou o processo de criação de duas RESEX marinhas no litoral centro-sul de Santa Catarina, e de Cardoso (2008) sobre a RESEX do Mandira em Cananéia (SP). Com exceção desse último, todos eles identificam desafios significativos para que esse tipo de arranjo seja eficaz em atingir seus objetivos. Dentre eles estão a existência de barreiras sociais para ação coletiva e a deficiência das instituições gestoras locais que, consequentemente, conduzem a participação incipiente dos pescadores na tomada de decisão sobre a gestão dos recursos pesqueiros (Silva, 2004). Adicionalmente, a preponderância dos 
objetivos de conservação da biodiversidade em relação aos objetivos de desenvolvimento local, usualmente defendida pela agência ambiental gestora, conduz também a baixos níveis de participação, de legitimidade política e de aprendizagem social nos espaços de decisão (Vivacqua, 2012).

O presente artigo aborda o caso da primeira RESEX constituída na zona costeiro-marinha brasileira, em 1992, a RESEX Marinha do Pirajubaé (SC), cujo território se encontra dentro dos limites urbanos da cidade de Florianópolis. Ela foi constantemente afetada pela dinâmica do crescimento urbano impulsionado, principalmente, pelo turismo (Souza, 2007; Karam, 2009; Vizinho \& Tognella-de-Rosa, 2010). Faz parte dessa dinâmica a construção da Via Expressa Sul, via rápida de ligação da região central à região sul da ilha de Florianópolis, que alcança a região limítrofe da RESEX. Para instalar esta via, entre 1995 e 1996, foi construído um aterro hidráulico que expandiu a área da planície costeira da enseada do Saco dos Limões e cujos impactos provocaram a redução dos estoques dos recursos pesqueiros dessa RESEX, dentre eles o berbigão (Anomalocardia brasiliana), considerado seu recurso chave. O regime de cogestão proposto pela RESEX foi chamado a enfrentar esse "fator externo" imputado ao sistema socioprodutivo sob sua responsabilidade. A análise dessa situação conduz à reflexão sobre a fragilidade dessa instituição para garantir, ou promover, a conservação e o uso sustentável dos recursos pesqueiros, diante dos interesses dos atores externos (Ostrom, 2000) que ameaçam a reprodução desses recursos. Para isso, foram utilizadas informações secundárias sobre a pesca artesanal e a situação socioambiental na RESEX do Pirajubaé, e dados primários levantados entre março de 2010 e outubro de 2011, através da observação direta nos espaços de tomada de decisão da cogestão que estavam sendo constituídos neste momento. Além disso, foram realizadas entrevistas semiestruturadas com gestores e extrativistas desta RESEX.

\section{A RESEX Marinha do Pirajubaé (SC)}

A RESEX Marinha do Pirajubaé, com aproximadamente 1.444 hectares, localiza-se na Enseada dos
Limões, na Baía Sul da ilha de Florianópolis, uma região estuarina e de manguezais na desembocadura do Rio Tavares, no município de Florianópolis, capital do Estado de Santa Catarina (Karam, 2009) (Figura 1).

A RESEX do Pirajubaé possui 109 extrativistas cadastrados, categorizados em três grupos de acordo com o grau de dependência socioeconômica que eles possuem em relação à extração dos recursos da RESEX. O grupo A, considerado o grupo dos beneficiários da RESEX, é constituído pelos extrativistas que dependem exclusivamente dos recursos pesqueiros existentes na reserva para garantir sua subsistência. O grupo B inclui aqueles extrativistas que apenas complementam renda com o extrativismo na RESEX. Já ao grupo C pertencem os extrativistas que não dependem economicamente da RESEX, mas possuem um vínculo histórico e cultural com ela. A RESEX possui Conselho Deliberativo, constituído em 2010, mas não possui Plano de Manejo, apenas uma Instrução Normativa que institui algumas regras para a exploração do berbigão que, atualmente, caracteriza-se como pequena produção mercantil (cf. Diegues, 1983).

Essa reserva apresenta uma peculiaridade em relação às outras RESEX marinhas do Brasil: encontra-se incrustada no perímetro urbano de uma capital. O processo de sua criação teve início em 1988, quando havia cerca de 100 famílias de extrativistas que desenvolviam a pesca artesanal, principalmente de camarão, e o extrativismo do berbigão (Anomalocardia brasiliana), uma espécie de molusco que habita os bancos de areia, ou baixios, da RESEX. Como é frequente em populações de pescadores de pequena escala, essas famílias constituíam um grupo socioeconomicamente desfavorecido (Brasil, 2002; Karam, 2009).

A pesca do camarão destacava-se em função do alto valor comercial e da abundância desse recurso pesqueiro na área. Contudo, a partir da construção do aterro hidráulico, a abundância do camarão foi significativamente reduzida e, consequentemente, a sua pesca (Souza, 2007). O extrativismo do berbigão com fins comerciais só se tornou viável a partir da década de 1980, com a introdução de um petrecho de pesca denominado "gancho", um artefato trazido pela empresa Maricá que tinha como objetivo o beneficiamento e a comercialização desse recurso principalmente para o sudeste do país. As dificuldades de captura desse molusco do 


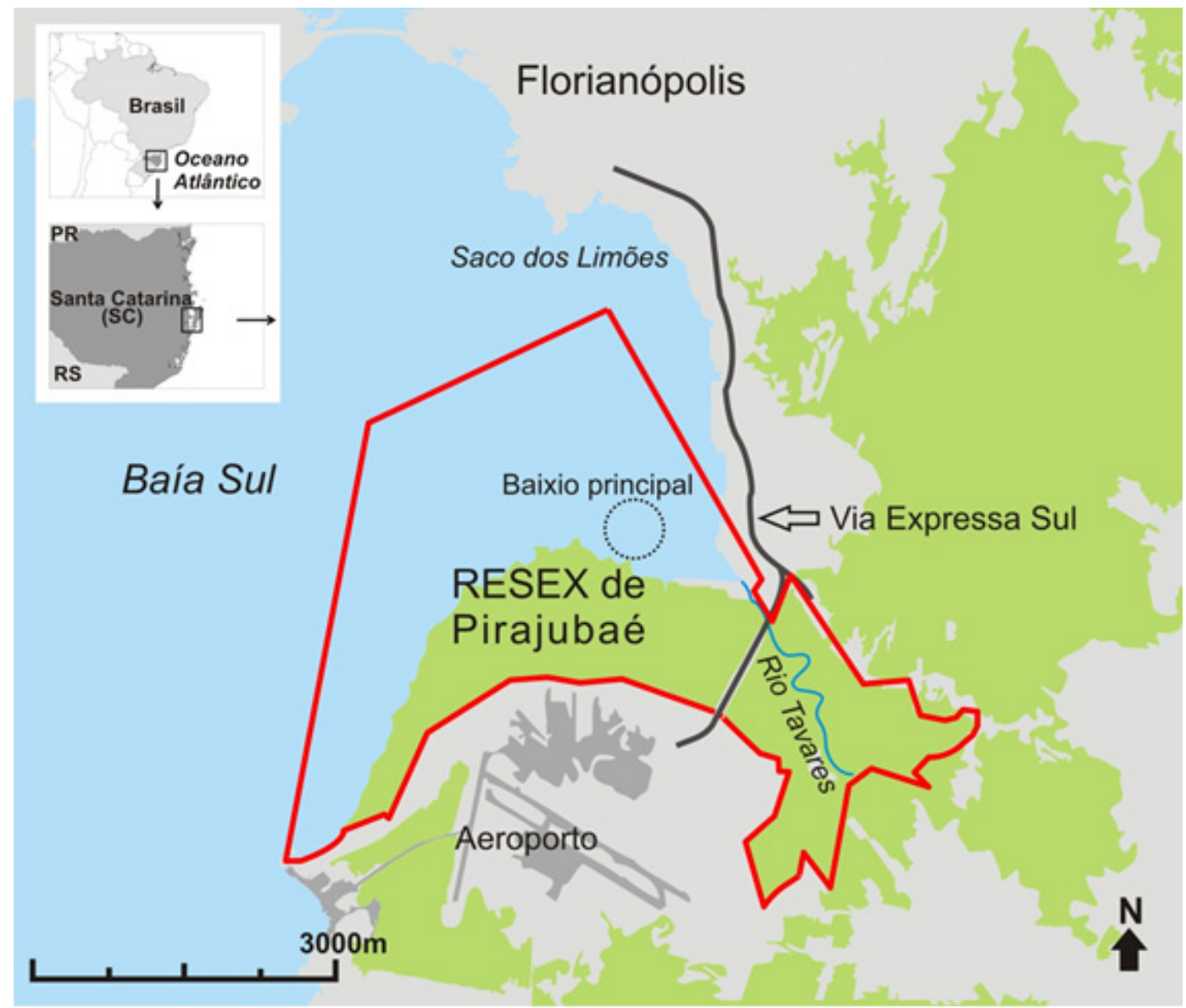

FIGURA 1 - Mapa esquemático da RESEX Marinha do Pirajubaé (polígono vermelho) e entorno na ilha de Florianópolis (SC). Indica-se parte da malha viária, incluindo o trecho da Via Expressa Sul, bem como outros elementos mencionados no texto. Em cinza, áreas urbanizadas ou fortemente alteradas; em verde, áreas vegetadas.

através da catação, o baixo preço e a falta de mercado não estimulavam a extração para fins comerciais do berbigão. O uso do "gancho" aumentou a eficiência da pesca e, assim, permitiu vencer os desafios da extração em maior escala para atender à comercialização crescente desse recurso. Entretanto, o "gancho" passou a ser utilizado de forma indiscriminada na enseada do Saco dos Limões, acarretando preocupações por parte de alguns extrativistas e da Superintendência do Desenvolvimento da Pesca (SUDEPE, hoje extinta), com o risco de sobre-exploração do recurso (Souza, 2007).

Diante disso, em 1988, foi instalado um projeto piloto de exploração sustentada do berbigão, a Fazenda Marinha de Berbigão, controlado pela SUDEPE. Esse projeto consistia na realização de estudos sobre os aspectos biológicos, tecnológicos e econômicos da extração do berbigão, envolvendo um grupo de pescadores, no baixio das Tipitingas que era uma área pouco explorada

${ }^{1} \mathrm{O}$ gancho é um equipamento rudimentar que consiste em uma cesta metálica, gradeada de modo a reter os berbigões, presa a um cabo de madeira, e cuja operação assemelha-se à de um arado (Tremel, 2001 apud Souza, 2007). 
pela população local na época. A partir de tais estudos criou-se um conjunto de diretrizes e de normas que visavam a garantir o uso sustentável do recurso nessa área (Souza, 2007).

Dessa iniciativa originou-se um grupo de extrativistas que propôs a continuidade da Fazenda, preocupados com a intensificação da exploração do berbigão devido à crescente demanda principalmente do mercado paulista. Em 1992, esse grupo, apoiado pela superintendência estadual do IBAMA, solicitou ao Conselho Nacional das Populações Tradicionais (CNPT) a realização de um estudo que subsidiasse a criação de uma RESEX nessa área (Souza, 2007). O documento assinado por 81 extrativistas solicitava que:

O Mangue do Rio Tavares e respectivo banco marinho anexo ao referido Mangue, onde extraímos nosso sustento (sururus, caranguejos, peixes, camarões, berbigões etc.) sejam transformados em Reserva Extrativista, considerando a necessidade de conservar ao longo do tempo os recursos naturais tradicionalmente explorados por nós. (apud Karam, 2009).

O IBAMA e a Fundação do Meio Ambiente de Santa Catarina (FATMA), a agência ambiental estadual, apoiaram a iniciativa de criação da RESEX, argumentando "a importância ecológica da conservação dos ecossistemas em questão, os manguezais do Rio Tavares, que são os maiores da Ilha de Santa Catarina" (Karam, 2009). Como resultado dessa mobilização, no mesmo ano foi criada a RESEX Marinha do Pirajubaé (Decreto $\mathrm{n}^{\mathrm{o}}$. 533, 20 de maio de 1992).

Em 1995, para institucionalizar o grupo acima citado, formou-se a AREMAPI - Associação da Reserva Extrativista Marinha do Pirajubaé. Seu objetivo era garantir a exploração sustentável da RESEX com a implantação de um plano de utilização desse recurso (Vizinho \& Tognella-de-Rosa, 2010). Esse plano foi aprovado em 1996 pelo IBAMA (portaria no 078/96) e, de maneira geral, mantinha as regras do referido projeto da Fazenda Marinha, que haviam sido construídas e, portanto, legitimadas junto ao grupo de extrativistas que utilizava a área e que as cumpriam. Tais regras incluíam seletividade de tamanho de captura; limitação do esforço de pesca através da fixação do número máximo de pescadores licenciados (12 a 18 pescadores), do número de dias por semana em que a extração era permitida (dois dias), e da quantidade de berbigão que poderia ser retirada por dia (5 a 8 latas de $18 \mathrm{~kg}$ por extrativista); além de estabelecer a rotatividade nas áreas de extração (Souza, 2007).

Nessa ocasião, os próprios extrativistas fiscalizavam o cumprimento das regras. A extração do berbigão era individual ou por núcleo familiar, mas a comercialização era realizada coletivamente para uma empresa que revendia o produto, principalmente, para o mercado paulista (Souza, 2007). A autofiscalização pelos extrativistas era realizada no cotidiano da prática extrativista e, também, no momento da quantificação diária da produção individual ou familiar destinada à comercialização coletiva. Quem não cumprisse as regras de uso do berbigão poderia ser punido com a exclusão deste processo coletivo de comercialização. Isso garantia uma relativa estabilidade ao extrativismo.

Em 1996, a construção da Via Expressa Sul afetou o processo de implementação da RESEX Marinha do Pirajubaé, gerando sérios impactos sobre a pesca artesanal nessa área e sobre o arranjo de cogestão, que regulava o extrativismo do berbigão, institucionalizado pelo referido plano de utilização.

\section{Os impactos da instalação da Via Expressa Sul sobre a RESEX Marinha do Pirajubaé (SC)}

A construção do aterro hidráulico para instalação da Via Expressa Sul na região adjacente à RESEX Marinha do Pirajubaé implicou a redução dos estoques de vários recursos pesqueiros, dentre eles o berbigão. A área habitada por esse molusco, e explorável pelos extrativistas, foi bastante reduzida. Esse impacto, por sua vez, culminou na desestruturação do regime que regulava o uso do berbigão e dificultou a continuidade da implementação do arranjo de cogestão que vigorava na área da RESEX.

A Via Expressa Sul é uma via de trânsito rápido, com seis pistas em dois sentidos, para ampliar e para facilitar o acesso da região central ao aeroporto de Florianópolis e às praias do sul desta ilha. Foi projetada pelo governo do estado de Santa Catarina e construída pela 
empresa CBPO Engenharia Ltda, empresa incorporada pela Odebrecht S.A.

Os principais impactos sobre os recursos da RESEX Marinha do Pirajubaé foram causados pela construção do aterro hidráulico para a ampliação de área terrestre para a Via Expressa Sul. O processo de Licenciamento Ambiental para a construção desse aterro, sob a responsabilidade do IBAMA, ocorreu concomitantemente à criação da RESEX. O Estudo de Impacto Ambiental (EIA) e o Relatório de Impacto Ambiental (RIMA) foram conduzidos inicialmente, em 1992, pela Universidade Federal de Santa Catarina (UFSC) e finalizados em 1994, por uma empresa de engenharia consultiva. Em 1995, as obras da Via Expressa Sul foram iniciadas sob a responsabilidade do Departamento de Estradas e Rodagem do Estado de Santa Catarina (DER/SC) que, posteriormente, foi extinto, sendo suas atribuições transferidas ao Departamento de Infraestrutura do Estado de Santa Catarina (DEINFRA/SC). O Monitoramento Ambiental, outro instrumento de controle ambiental exigido pelo Licenciamento Ambiental, foi realizado pela Universidade do Vale do Itajaí (UNIVALI). Esse monitoramento só foi iniciado após uma manifestação do Ministério Público Federal (MPF), ainda em 1996, que impetrou uma Ação Civil Federal após a constatação dos impactos socioambientais da obra.

O aterro hidráulico correspondeu a $1.198 .241 \mathrm{~m}^{2}$ de acrescido de marinha da área adjacente à RESEX. Sua construção implicou não apenas a supressão de ecossistemas aquáticos, como também a dragagem de uma grande quantidade de areia, matéria prima usada para construir o aterro, na Baía Sul (Figura 1). Segundo depoimentos dos extrativistas, a área removida, a que chamam "buraco da draga", é coincidente com os limites da RESEX. Porém, os pesquisadores que participaram do Monitoramento Ambiental do aterro hidráulico afirmam que a área removida não estava dentro dos limites da unidade, mas bastante próxima ${ }^{2}$. Além disso, grande parte do banco de areia de maior produtividade da RESEX teria deslizado para dentro do "buraco" (Karam, 2009).

A dragagem implicou a perda de sete milhões de metros cúbicos de areia da porção norte do baixio prin- cipal, onde ocorre preponderantemente o extrativismo do berbigão. Acarretou uma redução da área explorável de 240 para aproximadamente 140 hectares (Souza, 2007). Portanto, independente de coincidir, ou não, com os limites territoriais da RESEX, o impacto da obra sobre a biota afetou gravemente o estoque do berbigão.

Além do berbigão, muitos outros recursos pesqueiros foram afetados. Entre eles, destacam-se o camarão branco (Litopenaeus schmitti) e o camarão rosa (Farfantepenaeus brasiliensis), que têm naquele banco de areia e no manguezal do Rio Tavares, os estágios iniciais do seu ciclo de vida. Esse recurso era muito importante para população extrativista, do ponto de vista socioeconômico e cultural (Souza, 2007).

Os depoimentos dos extrativistas corroboram esta constatação. Segundo eles, antes da construção da Via Expressa Sul, a área da RESEX dispunha de grande abundância e variedade de recursos pesqueiros além do berbigão, e a pescaria de camarão representava parte significativa de suas fontes de renda. De acordo com depoimento de um extrativista:

\section{[...] a reserva foi criada por causa do berbigão [...] mas, dentro da reserva, o banco que dava o berbigão era também o maior produtor de camarão dessa região toda [...] o que a gente tirava na reserva, de tarrafa (referindo-se ao petrecho de pesca utilizado), saia na faixa de três a quatro toneladas por dia [...] (Extrativista da RESEX do Pirajubaé, 2011).}

Os primeiros resultados do programa de monitoramento da área impactada pelo empreendimento realizado pela UNIVALI reafirmaram os impactos da dragagem realizada. De acordo com Souza (2007) eles:

[...] indicaram que no fim de 1997 os níveis de biomassa
do berbigão atingiram patamares muito baixos, possi-
velmente por dois fatores: (a) a redução do tamanho do
estoque em função da diminuição da área do baixio,
aumentando o esforço de pesca sobre a espécie e; (b) o
fato do recurso não se distribuir de forma homogênea
pelo baixio das Tipitingas (estando as maiores biomassas

\footnotetext{
${ }^{2}$ Cabe destacar que as áreas do entorno de Unidades de Conservação, as zonas de amortecimento, também são protegidas pela legislação ambiental brasileira (BRASIL, 2000).
} 
no bordo externo que foi afetado pela dragagem), o que tornou a taxa real do estoque afetado pela obra da Via Expressa Sul, muito maior do que aquela originalmente considerada. (Souza, 2007, p. 8)

Os impactos do aterro hidráulico fizeram com que muitos dos extrativistas de berbigão buscassem ocupações em outras atividades econômicas para suprirem a renda originada do extrativismo (Souza, 2007).

Como informa a petição de ação civil pública

[...] após a construção do aterro hidráulico houve uma diminuição de pescadores atuantes, ou seja, antes do início da obra existiam aproximadamente 100 famílias dependendo diretamente da captura do berbigão e peixes. Hoje existem apenas 29 famílias dependendo da coleta de berbigão e peixes (Brasil, 2002).

Atualmente, em torno de 25 famílias vivem exclusivamente do extrativismo do berbigão (Karam, 2009) e constituem o grupo A, ou grupo dos beneficiários da RESEX, mencionado anteriormente.

Esse processo de evasão e de decadência da pesca e do extrativismo do berbigão, provavelmente, afetou a base de conhecimento local da população da RESEX. Segundo os extrativistas, muitos descendentes dos pescadores e/ou extrativistas desse molusco afastaram-se definitivamente da atividade de pesca e de extrativismo. Junto com eles, se perdeu parte do conhecimento sobre suas práticas produtivas. Esse conhecimento, transmitido oralmente de geração à geração torna-se vulnerável diante de transformações no processo produtivo (Gadgil et al., 2005).

Os extrativistas que não migraram para outras atividades fora da RESEX concentraram-se na extração do berbigão. Embora o estoque pesqueiro desse recurso tenha sido bastante impactado pela construção do aterro hidráulico, mesmo no início de 1997, o berbigão ainda era relativamente disponível na área da RESEX. Isto está relacionado à alta capacidade reprodutiva e à ampla distribuição deste recurso pesqueiro no baixio da RESEX. Todavia, sobre esta disponibilidade do berbigão, após a diminuição de sua abundância, os extrativistas aumentaram significativamente seu esforço de pesca para capturarem quantidade suficiente para a comercialização e, assim, manter a renda familiar decorrente do extrativismo desse recurso. Diante de tal situação, a maioria dos extrativistas da RESEX passou a não cumprir as regras estabelecidas pelo plano de utilização, ou seja, o regime que normatizava a pescaria do berbigão colapsou. O resultado foi uma grande pressão sobre o estoque restante desse molusco bivalve na área da RESEX (Souza, 2007).

A baixa no estoque populacional do berbigão em decorrência da intensificação da exploração não estava em sintonia com os objetivos de conservação dos recursos naturais da RESEX. Ao final de 1997, o IBAMA proibiu a extração desse recurso na RESEX (Souza, 2007), a atividade extrativista que justifica a sua própria existência. Esta atitude, considerada "de cima para baixo" ou tecnocrática (Vivacqua \& Vieira, 2005; Vieira et al., 2005), não é coerente com o arranjo institucional de cogestão previsto pela categoria RESEX. A decisão do IBAMA não considerou os interesses dos extrativistas através de processos participativos.

Ressalta-se que, neste período, a RESEX não estava implantada de fato e que o IBAMA não realizava ações de fiscalização na área da reserva e não exigia o cumprimento das condicionantes da Licença de Instalação (LI) da Via Expressa Sul. No período da construção do aterro, a RESEX Marinha do Pirajubaé ainda não possuía o Conselho Deliberativo. Este só se tornou obrigatório na RESEX a partir da regulamentação do SNUC, em 2000. No entanto, a AREMAPI já existia como instância representativa dos extrativistas, inclusive denunciando irregularidades e impactos da construção do aterro hidráulico, por exemplo, junto à Procuradoria da República. Em alguns casos foram obtidos resultados positivos, como as exigências de adequações técnicas para a redução dos impactos sobre os recursos pesqueiros e a redefinição de novas condições de validade da licença ambiental e de medidas compensatórias.

A proibição do IBAMA ao extrativismo colocou os extrativistas em condição de marginalidade e agravou ainda mais a situação de desregulação da extração do berbigão. Além de não acatarem a decisão do IBAMA, eles intensificaram seus esforços de pesca, visando a maximizar seus ganhos individuais imediatos.

À situação de instabilidade ambiental e social acrescenta-se a indefinição institucional em que se en- 
contrava a RESEX, acarretando o quadro de descontrole descrito por um extrativista:

[...] depois da Expressa Sul a reserva virou outro lugar. O que a gente conhecia já não existia mais e tudo que restou foram dúvidas [...] quero dizer que o conhecimento que a gente tinha já não servia mais. Ninguém sabia o que fazer, pois acabou o camarão, o peixe, e o berbigão diminuiu muito, o IBAMA não fazia nada, nem aparecia para conversar com os extrativistas sobre o que tava acontecendo com a reserva, e aí, os extrativistas tinham que sobreviver. Cada um foi dando seu jeito, quem ficou na pescaria tirava tudo que podia mesmo (referindo-se ao berbigão) do pouco que tinha sobrado depois da Expressa Sul. (Extrativista da RESEX do Pirajubaé, 2011).

Nessa situação, uma minoria dos extrativistas cumpre as regras de uso do berbigão instituídas e se sente prejudicada por aqueles que não o fazem, gerando desavenças entre esses dois grupos e instaurando-se um conflito que permanece até hoje na RESEX.

Outro conflito observado na RESEX gira em torno da competição e do enfrentamento entre os extrativistas da RESEX e os de localidades situadas na porção continental de Santa Catarina. Estes não possuem vínculo histórico com a exploração do berbigão na área da RESEX e, portanto, não detêm o direito de utilizar essa área para a exploração deste. No entanto, o fazem ilegalmente (Souza, 2007), desencadeando queixas por parte dos extrativistas da RESEX sobre a falta de fiscalização do ICMBio sobre a atuação dos extrativistas "externos".

De acordo com o depoimento de alguns extrativistas da RESEX, tal conflito só eclodiu após a redução do estoque de berbigão na RESEX, provocada pela instalação do aterro. Isso indica que é possível que a referida situação de desregulação do uso desse recurso, desencadeada por essa obra, associada à ineficácia da agência ambiental para fiscalizar a área, pode ter facilitado a presença dos extrativistas externos na área da RESEX. Ainda, estudos sobre o berbigão realizados pela UNIVALI afirmam que "a maior contribuição com o estoque desse recurso de toda a bacia norte e sul provém da Unidade de Conservação" (Karam, 2009, p. 44). Estima-se que $50 \%$ do total de produção da es- pécie nessa região são oriundos dos bancos de areia da RESEX (Karam, 2009). Essa área é fundamental para a manutenção do estoque, pois garante o povoamento do berbigão em outros bancos existentes na bacia norte e sul. É possível que a baixa na população de berbigão da RESEX, por causa da perda de grande parte do banco de areia principal, tenha provocado uma redução também da população da espécie em outras áreas litorâneas próximas à reserva, levando os extrativistas dessas áreas a buscarem a área da RESEX.

Corroborando as conclusões de Souza (2007), pode-se afirmar que a partir da instalação do aterro da Via Expressa Sul instaurou-se na RESEX uma situação em que as regras existentes não foram capazes de controlar o acesso aos recursos naturais de uso. Esse fato configurou uma situação de livre acesso de fato (Fenny et al., 2001), com o risco de acarretar a exaustão do estoque dos recursos da RESEX.

\section{A RESEX e a resistência aos impactos: no limite da Tragédia dos Comuns}

Na tentativa de contornar ou de minimizar a situação de desregulação do extrativismo do berbigão na RESEX, entre os anos de 2001 a 2005, foram realizadas algumas iniciativas institucionais. Visando a restabelecer um regime que regulasse o uso do berbigão na área da RESEX, três normativas para a exploração desse recurso foram criadas: a Portaria Emergencial de Ordenamento da Captura do Berbigão em 2003, a Instrução Normativa $n^{\circ} 19$, em 2004 e a Instrução Normativa n ${ }^{\circ} 81$ em 2005 (vigente até o início de 2012). Esta última, cuja formulação contou com a participação da UNIVALI e de um alguns poucos extrativistas que faziam parte do grupo que solicitou a criação da RESEX, previa as seguintes regras: redução no número de licenças; revezamento de áreas de exploração a fim de proteger o período de recrutamento de larvas no baixio principal dos possíveis efeitos deletérios do gancho; espaçamento mínimo do gradeamento para os ganchos e horário fixo para de pescaria (Souza, 2007).

No entanto, essa iniciativa não surtiu os efeitos esperados. Entre 2005 e 2006, o monitoramento constatou que a diversidade e os estoques populacionais de 
espécies de peixe e de camarão estavam se recuperando, o que não ocorria no caso do berbigão (Souza, 2007; Karam, 2009). Mesmo conhecendo as regras que então se estabeleceram para o uso do berbigão, parte dos extrativistas ainda optava por explorar o máximo possível por dia de trabalho na RESEX. A justificativa para não adotar estratégias exploratórias mais sustentáveis era que sem a fiscalização por parte da agência gestora, hoje o ICMBio, não havia como evitar que tais excedentes não fossem apropriados por outros usuários, conforme vinha ocorrendo, segundo depoimentos dos extrativistas:

[...] o problema é que se a gente não tirar (referindo-se ao berbigão) outros vêm e tiram do mesmo jeito e, às vezes, nem são extrativistas da RESEX [...] ai quem é extrativista da RESEX não tá cumprindo as regras mesmo [...]. (Extrativista da RESEX do Pirajubaé, 2011)

Segundo os extrativistas, a falta de fiscalização permite que alguns burlem as regras para aumentar a produtividade e, consequentemente, a renda mensal, sem sofrer punições. Além disso, abre caminho para a exploração do berbigão por extrativistas que não têm o direito de usar a área da reserva para o extrativismo. De acordo com alguns relatos, as iniciativas para reprimir esse tipo de conduta não são respeitadas pelos infratores que não têm o direito de utilizar a RESEX e, em muitos casos, reagem com ameaças de violência.

O poder e a responsabilidade de fiscalizar e de punir as infrações, ou seja, autuar os usuários infratores, é do ICMBio. Se os arranjos institucionais que regulam o uso dos recursos naturais de uso comum falham e a agência governamental não cumpre a sua função, como ocorreu na RESEX do Pirajubaé, não restarão outras formas de sancionar aqueles usuários que, por ventura, venham a descumprir as regras de uso. Ainda que possa explicar os caminhos que tomaram a exploração do berbigão, essa constatação não justifica as infrações cometidas pelos próprios extrativistas dessa reserva. Contudo, em situações na quais a competição pelos recursos naturais é muito acirrada, inclusive com usuários que não fazem parte da população extrativista, como a relatada acima, a ausência da fiscalização pelo ICMBio torna-se um obstáculo para reestabelecer a regulação para o uso sustentável dos recursos naturais. Sem entrar no mérito das condições da agência ambiental gestora para cumprir suas funções, a fragilidade da fiscalização é uma característica que persiste na RESEX do Pirajubaé. Junto à ausência de arranjos institucionais efetivos, a ausência de fiscalização intensifica o quadro de sobre-exploração do recurso, tal como apontado por Souza (2007).

Nesse cenário, os conflitos em torno da apropriação do berbigão, tanto entre os próprios extrativistas da RESEX como com os extrativistas que não possuem o direito de utilizar a reserva para explorar o berbigão, persistem e se exacerbam nos dias atuais.

Constata-se que existem acentuados problemas para regular o acesso e o uso dos recursos naturais comuns e, portanto, para reverter a situação de livre acesso à RESEX do Pirajubaé. Isso significa que a RESEX, enquanto um arranjo de cogestão, não vem obtendo sucesso no sentido de evitar a propalada tragédia dos comuns nessa área.

A RESEX do Pirajubaé exemplifica uma situação ambiental em que instituições comunitárias são desestruturadas por determinados projetos de desenvolvimento guiados por interesses políticos e econômicos de grupos sociais dominantes. Um dos objetivos principais da categoria RESEX é justamente garantir a continuidade de tais instituições com o apoio do Estado. Esta parece uma situação bastante distante daquela de Pirajubaé, na ocasião da instalação do aterro da Via Expressa Sul. A RESEX do Pirajubaé já havia sido instituída e, ainda assim, sua importância ecológica, socioeconômica e cultural não foi considerada. Diante dessa situação, os extrativistas da RESEX recorreram ao Ministério Público Federal, que impetrou a Ação Civil Pública contra o Estado de Santa Catarina, a empresa construtora e o IBAMA. Referindo-se à autorização para instalação do aterro da Via Expressa Sul, concedida pelo IBAMA, a petição desta Ação Civil esclarece:

[...] em um primeiro grande equívoco, extrapolou o órgão ambiental das funções expressas para as quais havia sido nomeado espécie de "tutor" da unidade de conservação federal, quais sejam à preservação dos recursos naturais, e sua utilização exclusiva para os projetos extrativistas de interesse de toda comunidade (Brasil, 2002). 
A instalação da Via Expressa Sul provocou a desestruturação do regime que garantia o uso sustentável do berbigão na RESEX, mesmo ela sendo um arranjo institucional formal de cogestão dos recursos naturais comuns. Como explicado acima, as ações da agência ambiental, que era a "cogestora" e deveria zelar pela integridade dos ecossistemas e dos arranjos socioprodutivos dessa reserva, agravaram esta situação. Isso indica que a criação desse tipo de instituição formal, por si só, não é capaz de garantir o surgimento ou a permanência de arranjos institucionais que permitem o uso sustentável dos recursos pesqueiros.

Contudo, em 2011, um novo esforço do ICMBio e de um grupo de extrativistas para reestabelecer um regime que regule a exploração do berbigão na RESEX foi empreendido. Essa iniciativa refere-se à revisão da IN $\mathrm{N}^{o} 81$, realizada através de uma oficina que contou com a participação do ICMBio, da UNIVALI e do grupo de extrativistas que, já a época, encontravam-se organizados na Associação Caminhos do Berbigão (ACBer). Essa associação foi criada em 2002 para representar os interesses dos extrativistas da RESEX já que AREMAPI estava inativa.

A nova versão da IN produzida nessa oficina foi aprovada pelo Conselho Deliberativo que havia sido recentemente constituído. Essa normativa foi resultado de um processo efetivamente participativo e de aprendizado, caracterizado pelo diálogo entre o conhecimento científico acumulado em 12 anos de estudos acerca da biologia reprodutiva do berbigão nessa área, produzidos pelos pesquisadores da UNIVALI, e o conhecimento local dos extrativistas sobre a vida e o extrativismo do berbigão na RESEX. O modo como foi produzida a torna mais legítima e, possivelmente, mais efetiva do que as normativas anteriores, no sentido de regular a pescaria e retomar o uso sustentável do berbigão na RESEX. Entretanto, o processo de regulamentação do uso dos recursos só se completa quando os extrativistas e ICMBio cumprem suas partes no acordo que fundamenta essa nova normativa. Mesmo assim, isso não elimina a vulnerabilidade dos arranjos de cogestão - um processo contínuo de gestão e de aprendizado (Macedo, 2008; Berkes, 2009) - diante dos impactos de fatores externos ao sistema socioprodutivo que representam interesses econômicos e políticos capazes de se sobrepor aos interesses estabelecidos no processo de cogestão.
Outros aspectos como, por exemplo, as fragilidades das instituições governamentais ambientais para a gestão de suas unidades de conservação e das resistências coletivas de populações tradicionais àquelas ações e/ou projetos que ameaçam sua reprodução social, o valor dado ao meio ambiente nas políticas de desenvolvimento nos diferentes níveis administrativos, além de outros fatores, tornam os arranjos de cogestão ainda mais vulneráveis aos impactos dos "fatores externos".

\section{Considerações finais}

A RESEX Marinha do Pirajubaé, distintamente das outras RESEX marinhas dos Brasil, enfrenta o desafio de encontrar-se inserida no perímetro urbano de uma capital e de ter a integridade socioambiental de seu território ameaçada pelos processos de expansão urbana e pelos projetos de desenvolvimento.

O empreendimento Via Expressa Sul prejudicou substancialmente as atividades de pesca e de extrativismo na RESEX do Pirajubaé e negligenciou os direitos da população extrativista sobre esse território, direitos estes que deveriam ser assegurados pela instituição RESEX. Os impactos socioambientais resultantes da construção do aterro hidráulico da Via Expressa Sul sobre esta RESEX são inegáveis, e uma de suas consequências foi a desestruturação do arranjo institucional que regulava a pescaria do berbigão e que promovia uso sustentável deste recurso na área.

Acredita-se que o esforço conjunto dos gestores (ICMBio), pesquisadores e extrativistas para reestruturar a normativa que regula a pescaria do berbigão na RESEX marinha do Pirajubaé, em 2011, poderia obter maior sucesso do que as ações de gestão anteriores no sentido de reverter a situação de livre acesso em que se encontrava a área da reserva. A participação efetiva dos extrativistas na produção dessa nova versão da normativa a tornou mais legítima e proporcionou maiores chances de cumprimento das regras estabelecidas por eles. Contudo, não há garantia de que essa mudança ocorra. Diante disso, o acompanhamento, pela pesquisa, da implementação e das consequências dessa nova versão da instrução normativa é altamente relevante para a compreensão dos limites e das possibilidades da RESEX do Pirajubaé, enquanto 
ferramenta de cogestão, para promover o uso sustentável do berbigão nessa área e, portanto, garantir a reprodução social desta população extrativista.

Considera-se ainda, que uma série de fatores desafia arranjos institucionais formais de cogestão. Muitas vezes, esses arranjos são criados juridicamente, mas sua implementação é dificultada ou é desestabilizada por iniciativas que atendem a interesses de grupos privilegiados, como foi o caso da RESEX Marinha do Pirajubaé.

Assim, a RESEX, bem como outros arranjos formais de cogestão, é vulnerável aos efeitos negativos

\section{Referências}

Berkes, F. Evolution of co-management: role of knowledge generation, bridging organizations and social learning. Journal of Environmental Management, 90, 1692-1702, 2009.

Berkes, F. From community-based resource management to complex systems: the scale issue and marine commons. Ecology and Society, 11(1), 45, 2010. Disponível em: http://www. ecologyandsociety.org/vol11/iss1/art45/.

Berkes, F.; Fenny, D.; McCay, B. J.; Acheson, J. M. The benefits of the commons. Nature, 340, 91-93, 1989.

Brasil. Presidência da República. Lei no 9.985, de 18 de julho de 2000. Regulamenta o art. 225, $\S 1^{\circ}$, incisos I, II, III e VII da Constituição Federal, institui o Sistema Nacional de Unidades de Conservação da Natureza e dá outras providências. DOU. 19/07/2000.

Brasil. Ministério Público Federal. Petição de Ação Civil Pública, processo $n^{\circ}$ 2002.72.007815-6. Florianópolis, 2002.

Cardoso, T. A. A construção da gestão compartilhada da Reserva Extrativista do Mandira, Cananéia, SP. Tese (Doutorado em Ecologia e Recursos Naturais). Centro de Ciências Biológicas e Saúde, Universidade Federal de São Carlos, São Carlo, SP. 2008.

Chamy, P. Reservas Extrativistas Marinhas como instrumento de reconhecimento do direito consuetudinário de pescadores artesanais brasileiros sobre territórios de uso comum. In: Anais $d a$ Conference of the International Association for the Study of Common Property: The Commons in an Age of Global Transition: Challenges, Risks and Opportunities. México, 2004. Disponível em: $<$ http://www.ibcperu.org/doc/isis/5275.pdf $>$.

Diegues, A. C. O Desenvolvimento da pesca no Brasil e suas contradições. Capítulo VIII - Ensaio de Tipologia das formas de fatores externos. Sua capacidade de resistir a eles depende de condições institucionais como, por exemplo, o comprometimento da agência ambiental gestora e a participação efetiva da população extrativista no processo de gestão. Embora não haja garantias de que esses arranjos resistam a tais fatores, considera-se que a sua existência engendra melhores chances de assegurar ou de reestabelecer o uso sustentável dos recursos naturais, evitando a tragédia dos comuns e, portanto, garantindo a reprodução social das populações extrativistas.

de organização da produção da pesca. In: Diegues, A.C. (Org.). Pescadores, camponeses e trabalhadores do mar. São Paulo: Ática, p. 148 -156, 1983.

Dietz, T.; Dolsak, N.; Ostrom, E.; Stern, P. C. The drama of the commons. Washington: National Academy Press, 2002.

Fenny, D.; Berkes, F.; McCay, B. J.; Acheson, J. M. A Tragédia dos comuns: vinte e dois anos depois. In: Diegues, A.; Moreira, A. C. (Orgs.). Espaços e recursos de uso comum. São Paulo: NUPAUB-USP, p. 17- 42, 2001.

Gadgil, M.; Seshagiri Rao, P. R.; Utkarsh, G.; Pramod, P.; Chhatre, A. Novos significados para antigos conhecimentos: O programa de registros participativos da biodiversidade. In: Vieira, P. F; Berkes, F; Seixas, C. S. (Orgs.). Gestão integrada e participativa de recursos naturais: conceitos, métodos e experiências. Florianópolis- Secco/APED, p.261-286, 2005.

Hardin, G. The tragedy of the commons. Science, 162, 12431248, 1968.

Kalikoski, D. C. Áreas marinhas protegidas, conservação e justiça social: considerações à luz da teoria dos comuns. In: Ministério do Meio Ambiente (Org.). Áreas aquáticas protegidas como instrumento de gestão pesqueira. Brasília: MMA, p.55-68, 2007.

Karam, K. F. Documento consolidado da caracterização da reserva extrativista do Pirajubaé com indicação de estudos prioritários e subsídios para construção do plano de utilização e programas de sustentabilidade. Projeto PNUD/BRA/99/024, MMA/ICMBio, Florianópolis, 2009. 90p.

Macedo, H. S. Processos participativos na gestão de áreas protegidas: estudo de caso em unidades de conservação de uso 
sustentável da zona costeira do Sul do Brasil. Florianópolis, Dissertação (Mestrado em Sociologia Política). Centro de Filosofia e Ciências Humanas, Universidade Federal de Santa Catarina, 2008.

McKean, M. Success on the commons. Journal of Theorical Politics, 4(3), 247-281, 1992.

McKean, M. Common property: what is it, what is it good for, and what makes it work? In: Clark, C.; McKean, M.; Ostrom, E. (Eds.). People and forests: communities, institutions and governance. Cambridge, MA: Mit Press. 2000. p. 29-51.

Medeiros, R. P. Possibilidades e obstáculos à cogestão adaptativa de sistemas pesqueiros artesanais: estudo de caso na área da Baía de Tijucas, litoral centro-norte do estado de Santa Catarina, no período de 2004 a 2008. Florianópolis, Tese (Doutorado em Sociologia Política). Centro de Filosofia e Ciências Humanas, Universidade Federal de Santa Catarina, 2009.

Ostrom, E. El gobierno de los bienes comunes: la evolución de las instituciones de acción colectiva. México: Universidade Nacional Autonóma do México, 2000.

Prost, C. Ecodesenvolvimento da pesca artesanal em região costeira - estudos de caso no Norte e Nordeste do Brasil. GeoTextos, 3(1 e 2), 139-169, 2007.

Prost, C. Resex marinha versus polo naval na baía do Iguape. Novos Cadernos NAEA, 13(1), 47-70, 2010.
Silva, P. P. From common property to co-management: lessons from Brazil's first maritime extractive reserve. Marine Policy, 28, 419-428, 2004.

Souza, D. S. Caracterização da pescaria do berbigão Anomalocardia brasiliana (Gmelin, 1791) (Mollusca: Bivalvia) na Reserva Extrativista Marinha de Pirajubaé (Florianópolis/ $S C$ ): subsídios para o manejo. Itajaí, Dissertação (Mestrado em Ciência e Tecnologia Ambiental) - Centro de Ciências Tecnológicas da Terra e do Mar, Universidade do Vale do Itajaí, 2007.

Vieira, P. F; Berkes, F; Seixas, C. S. Gestão integrada e participativa de recursos naturais: conceitos, métodos e experiências. Florianópolis: Secco/APED. 2005.

Vivacqua, M.; Vieira, P. F; Conflitos socioambientais em Unidades de Conservação. Politica e Sociedade, 4(7), 139$162,2005$.

Vivacqua, M. Dilemas da conservação e desenvolvimento na gestão compartilhada da pesca artesanal: conflitos e sinergias nos processos de criação de reservas extrativistas marinho-costeiras em Santa Catarina. 2012, 357f. Florianópolis, Tese (Doutorado em Sociologia Política). Centro de Filosofia e Ciências Humanas, Universidade Federal de Santa Catarina, 2012.

Vizinho, S. C.; Tognella-de-Rosa, M. M. P. Análise sócio-econômica e cultural da comunidade pesqueira do Pirajubaé (Baía Sul - Florianópolis - Santa Catarina - Brasil): uma ferramenta para o gerenciamento costeiro integrado. Revista de Gestão Costeira Integrada, n. especial 2, Manguezais do Brasil, 2010. 